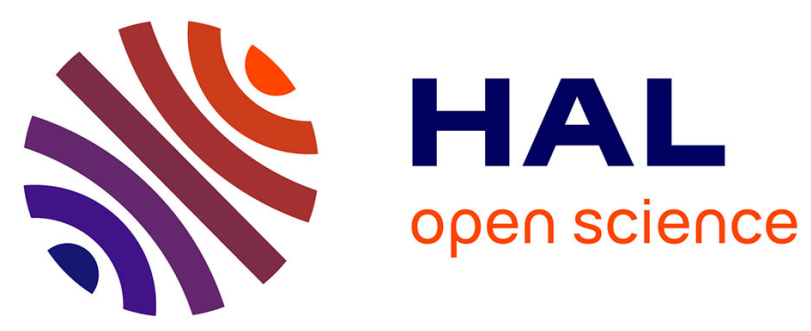

\title{
XAS Study on the Intermediate Species Formed During the Surface Oxidation of CrN Films
}

F. Esaka, K. Furuya, H. Shimada, M. Imamura, N. Matsubayashi, T. Sato, A. Nishijima, T. Kikuchi, A. Kawana, H. Ichimura

\section{> To cite this version:}

F. Esaka, K. Furuya, H. Shimada, M. Imamura, N. Matsubayashi, et al.. XAS Study on the Intermediate Species Formed During the Surface Oxidation of CrN Films. Journal de Physique IV Proceedings, 1997, 7 (C2), pp.C2-1149-C2-1150. 10.1051/jp4:19972167 . jpa-00255231

\section{HAL Id: jpa-00255231 https://hal.science/jpa-00255231}

Submitted on 1 Jan 1997

HAL is a multi-disciplinary open access archive for the deposit and dissemination of scientific research documents, whether they are published or not. The documents may come from teaching and research institutions in France or abroad, or from public or private research centers.
L'archive ouverte pluridisciplinaire HAL, est destinée au dépôt et à la diffusion de documents scientifiques de niveau recherche, publiés ou non, émanant des établissements d'enseignement et de recherche français ou étrangers, des laboratoires publics ou privés. 


\title{
XAS Study on the Intermediate Species Formed During the Surface Oxidation of CrN Films
}

\author{
F. Esaka, K. Furuya, H. Shimada*, M. Imamura*, N. Matsubayashi*, T. Sato, A. Nishijima*, \\ T. Kikuchi**, A. Kawana*** and H. Ichimura***
}

\author{
Department of Applied Chemistry, Faculty of Science, Science University of Tokyo, 1-3, Kagurazaka, \\ Shinjuku-ku, Tokyo 162, Japan \\ * National Institute of Materials and Chemical Research, 1-1, Higashi, Tsukuba, Ibaraki 305, Japan \\ ** Science University of Tokyo in Yamaguchi, 1-1-1, Daigakudori, Onoda, Yamaguchi 756, Japan \\ *** Sumitomo Metal Mining Co. Ltd., 3-18-5, Nakakokubun, Ichikawa, Chiba 272, Japan
}

\begin{abstract}
XAS was applied to the identification of the intermediate species formed during the surface oxidation of $\mathrm{CrN}$ films. The N K-edge XAS spectra indicated formation of an intermediate species which gave a feature at $401.4 \mathrm{eV}$. A high resolution XAS spectrum exhibited that the feature at $401.4 \mathrm{eV}$ has the same vibration splitting as that of gaseous $\mathrm{N}_{2}$. It was also found that the species assigned to molecular $\mathrm{N}_{2}$ occurred in the interstitial position of the surface oxide layer in the oxidized films. The result implied the importance of high energy resolution XAS in the field of material science.
\end{abstract}

\section{INTRODUCTION}

$\mathrm{CrN}$ is used for surface coatings to improve the hardness and corrosion resistance of various mechanical tools. During the use under an oxidizing atmosphere at a high temperature, these film properties fail due to the formation of surface oxide layer. There have been several studies on the surface oxidation mechanisms of CrN films [1], however, no detailed discussion was carried out on the intermediate species during surface oxidation. In previous reports $[2,3]$, we investigated the surface oxidation of $\mathrm{CrN}$ films by $\mathrm{x}$-ray absorption spectroscopy (XAS) and suggested that molecular $\mathrm{N}_{2}$ is formed in the interstitial position of the surface oxide layer. The purpose of the present study is to obtain the evidence which shows that the intermediate species is molecular $\mathrm{N}_{2}$. In addition, in-depth distribution of the nitrogen species is investigated by changing the analysis depth of XAS.

\section{EXPERIMENTAL PROCEDURE}

$\mathrm{CrN}$ films with a thickness of $3 \mu \mathrm{m}$ were deposited on austenite stainless steel by a cathodic arcion-plating method. The deposition procedures were described in detail in a previous report [4]. Surface oxidation of the $\mathrm{CrN}$ film was performed at $400{ }^{\circ} \mathrm{C}$ for $1 \mathrm{~h}$ in a flow of dry air $\left(50 \mathrm{~cm}^{3} / \mathrm{min}\right.$.). All XAS measurements were performed at the BL-13C of the Photon Factory [5]. The angle between the incident $X$-ray and the sample surface was set at $90^{\circ}$. XAS spectra were recorded with total electron yield (TEY), partial electron yield (PEY) with a retarding voltage of $270 \mathrm{~V}$ and $\mathrm{x}$-ray fluorescence yield (FY) modes. All the spectra were normalized by dividing the signals by the signals recorded by a gold mesh located at the upstream side of the sample.

\section{RESULTS AND DISCUSSION}

Fig. 1 shows the N K-edgeXAS spectra of the CrN films before and after surface oxidation. The TEY spectrum of the film before surface oxidation exhibits only the features assigned to CrN. In the PEY and TEY spectra of the oxidized film, a sharp feature attributed to an intermediate species is observed at $401.4 \mathrm{eV}$ with a full width at half maximum (FWHM) value of $0.7 \mathrm{eV}$ besides the CrN features. This feature is scarcely observed in the FY spectrum. Probing depths for each detection mode is $<20 \AA$ in PEY, 20-100 $\AA$ in TEY and $>1000 \AA$ in FY. This indicates that the intermediate species is present predominantly in the surface oxide layer of the oxidized film.

In previous reports [2,3], we assigned the feature at $401.4 \mathrm{eV}$ to molecular $\mathrm{N}_{2}$ by comparing the photon energies of the features. To confirm the assignment, $\mathrm{N}$ K-edge XAS spectra of gaseous $\mathrm{N}_{2}$ have been measured and compared with that of the oxidized film as shown in Fig. 2. The obtained spectra are fitted by a least-square method using mixed Gaussian-Lorentzian envelopes with a fixed Lorentzian width of $128 \mathrm{meV}$. The obtained Gaussian width corresponds to the line-width of the incident $\mathrm{x}$-ray, indicated as 
$\Delta \mathrm{E}$ in Fig. 2. When the entrance and exit slit widths are quite narrow, well split vibration structures are observed as shown in Fig. 2(c). However, the signal intensity from the oxidized film is not high enough to measure the spectrum under the same instrumental conditions. Thus, the spectrum is compared with the spectrum of molecular $N_{2}$ measured at a moderate energy resolution of $\Delta E$ $=210 \mathrm{meV}$. The comparison evidently indicates that the intermediate species in the oxidized film is molecular $\mathrm{N}_{2}$. The vibration splitting precludes the formation of atomic nitrogen which was suggested by Soriano et al. [6].

In conclusion, the present high resolution XAS result has confirmed the assignment that the intermediate species in the oxidized $\mathrm{CrN}$ film is molecular $\mathrm{N}_{2}$. This indicates the importance of the high resolution XAS for material science. In addition, it is found that XAS can be used for acquiring in-depth information by using various detection modes.

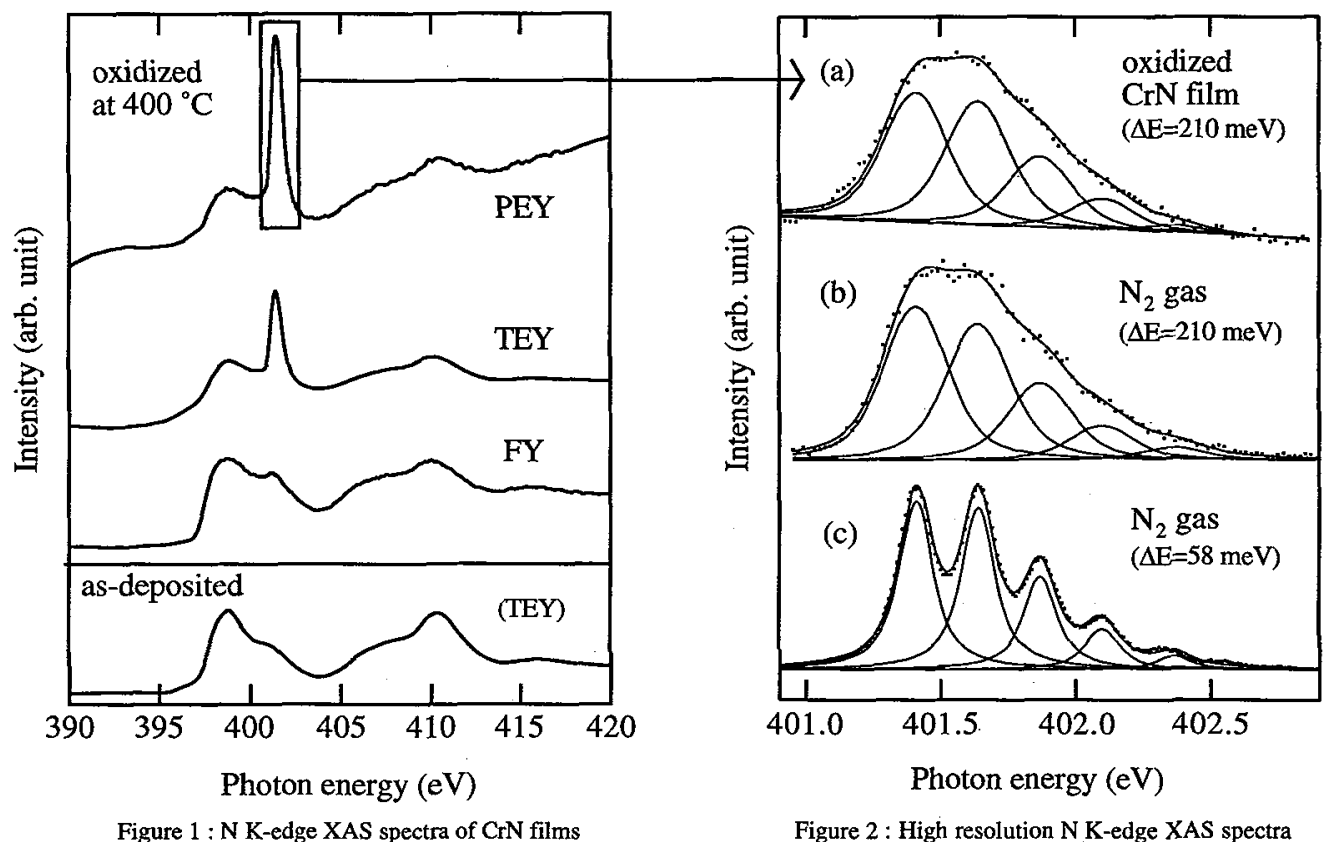
before and after surface oxidation of oxidized $\mathrm{CrN}$ film and $\mathrm{N}_{2}$ gas

\section{Acknowledgements}

This work has been performed with the approval of the Photon Factory Programme Advisory Committee (PF-PAC No. 96-G144). F. E. was grateful for the Research Fellowships of the Japan Society for the Promotion of Science for Young Scientists.

\section{References}

[1] S. Hofmann and H. A. Jehn, Surf. Interface Anal. 12 (1988) 329-333.

[2] F. Esaka, H. Shimada, M. Imamura, N. Matsubayashi, T. Sato, A. Nishijima, A. Kawana, H. Ichimura, T. Kikuchi and K. Furuya, Thin Solid Films, in printing.

[3] F. Esaka, H. Shimada, M. Imamura, N. Matsubayashi, T. Sato, A. Nishijima, A. Kawana, H. Ichimura, T. Kikuchi and K. Furuya, J. Vac. Sci. Technol. A, submitted.

[4] H. Ichimura and A. Kawana, J. Mater. Res. 9 (1994) 151-155.

[5] N. Matsubayashi, H. Shimada, K. Tanaka, T. Sato, Y. Yoshimura and A. Nishijima, Rev. Sci. Instrum. 63 (1992) $1363-1366$.

[6] L. Soriano, M. Abbate, J. C. Fuggle, C. Jimenez, J. M. Sanz, L. Galan, C. Mythen and H. A. Padmore, Surf. Sci. 281 (1993) 120-126. 